\title{
POINT LED LIGHT SOURCES ATTACHED ON THE FEEDERS AND DRINKERS, AS AN ILLUMINATION SYSTEM IN BROILER HOUSES: EFFECTS ON BROILER PERFORMANCE
}

\author{
B. Yeter \\ Department of Animal Science, Faculty of Agriculture, University of Kahramanmaras Sutcu Imam, Kahramanmaras, \\ Turkey \\ Corresponding author's email: byeter@gmail.com
}

\begin{abstract}
The experiment was carried out to evaluate effects of point Light Emitting Diode (LED) lights source attached to the feeders and drinkers on the broiler performance compared with the standard ceiling with the bulb in environment controlled house with two clusters. Total of 3360 chicks were divided into 2 groups (control and experimental) consisting 3 replicates of 560 chicks with $12.5 \mathrm{birds} / \mathrm{m}^{2}$ stocking density. Although, light intensity was measured as 18 lux at the level of feeders for the control group, it was measured 82 lux inside the feeders, 12 lux at the outer edge of them, while the measuring was showing 1 lux at $15 \mathrm{~cm}$ distance from the feeders 8 lux at the water dropper and zero in other areas for the experimental group. Standard rearing techniques and commercial diets were used during experimental period and parameters such as growth performance, feed conversion ratio (FCR) and mortality of broiler chicks were determined. The mean chick weight at the beginning of the experiment was similar in the control and experimental groups. There was no difference between lighting applications at the age of first week, however, at later stages, body weight $(\mathrm{BW})$ was recorded significantly higher $(\mathrm{P} \leq 0.05, \mathrm{P} \leq 0.01)$ in LED illumination treated group compared to control group. No significant differences were observed in feed intake and FCR between lighting treatments. In 42 day old, feed conversion ratios in control and LED lighting treated group were determined as 1.651 and 1.607 , respectively $(\mathrm{P}>0.05)$. The mortality rates of control and LED lighting treated groups were found to be 5.24 and $3.51(\mathrm{P} \leq 0.05)$ at the age of 42 days. No negative effect of Point LED lights system on weekly body weight gain, feed intake, and feed conversion ratios were observed, but a positive effect on cumulative body weight and mortality. Therefore, pointed LED can be used as a lighting system in broiler production being cost effective without compromising the productive performance.
\end{abstract}

Key words: Broiler, Lighting, Pointed LED, Performance.

https://doi.org/10.36899/JAPS.2021.1.0189

Published online August 26, 2020

\section{INTRODUCTION}

Lighting, an extremely significant environmental and primary microclimate factor in poultry production, plays a pivotal role for the release of various hormones that influence growth, development and physiological functioning (Olanrewaju et al., 2006; Baser and Yetisir, 2010; Ahmad et al., 2011; Yang et al., 2015; Olanrewaju et al., 2016; Zhao et al., 2019). Physiological activities and behavioural processes of birds are externally controlled by lighting programs (Brown, 2010; Mahmood et al., 2014; Pandey, 2019). Therefore, light source, intensity and lighting programs are significant management tools to regulate broiler production and welfare, playing an important role in broiler's health (Deep et al., 2010; Blatchford et al., 2012; Olanrewaju et al., 2016). In animal husbandry sector and especially in broiler production, research on animal welfare is raising awareness (Raccoursier Frost, 2016).

Lighting program is a strategic application used in broiler production aiming at reducing the incidence of metabolic and skeletal disorders in broiler chickens (Olanrewaju et al., 2014 a). Although it is possible to classify lighting programs from different angles, a classification made in the form of continuous, discrete and restricted lighting programs is in practice (Baser and Yetisir, 2010). It has been found that continuous light application, which has been widely used in broiler breeding, creates stress in animals (Rozenboim et al., 2010; Classen et al., 2010). Reduced lighting time and light intensity decreases mortality rates (Classen and Riddell, 1989; Renden et al., 1991; Blair et al., 1993; Sanotra et al., 2002; Olanrewaju et al., 2006). However, some studies show that mortality rates are not affected by lighting treatments (Olanrewaju et al., 2014a; 2014b, 2016; Evrim et al., 2017).

Recently, incandescent and fluorescent Light Emitting Diode (LED) lighting have become more preferable instead of conventional light source in broiler production (Archer, 2015), benefits of this replacement include decrease in energy use, increase in bird performance and improvement in bird welfare. (It is also stated that different light sources and intensity have an 
ffect on fear and stress in broiler production (Archer, 2015; Huth and Archer, 2015).

For this reason, LED light sources were used in this study in order to create light and dark areas in the experimenting field.LED light sources were installed in isolation with the means of being located at thefeeders and drinkers separating them from the poultry house. This endeavour was to provide enough lighting for broilers to satisfy the needs of food and water, while, the rest of the house was kept at the dark. This study was carried out to determine the impact of applied lighting systems on broiler's performance of growth.

\section{MATERIALS AND METHODS}

The present study was carried out in Kahramanmaraş Sütçü İmam University, Animal Production Application and Research Center with the permission of KSU, Faculty of Agriculture, Animal Experiments Local Ethics Committee 2013/05-02. Poultry houses were sized as $7 \times 19 \mathrm{~m}$, concrete floor, two sides plastered, pumice wall, sandwich panel roofed houses. The height of the wall was $3 \mathrm{~m}$, the height of the ridge was $4.2 \mathrm{~m}$. It was closed with a metal wire mesh at a distance of $1.5 \times 1.5 \mathrm{~cm}$ which is fixed to a metal frame of $60 \mathrm{~cm}$ height between the replicates. The houses were divided into three sections with tarpaulin curtains and chicks were placed on $1 / 3$ of the space allocated for each repetition. The poultry houses were fully controlled closed and the ventilation system contained inlet, fan and pads. It isattempted to provide fresh air in the house. For $1 \mathrm{~kg}$ body weight, $1 \mathrm{~m}^{3} /$ hour of fresh air is delivered in the first week, $1-1.5 \mathrm{~m}^{3} /$ hour in the 2 nd week, and $1.5-2$ $\mathrm{m}^{3} /$ hour in the following weeks.

For the experiment, mixed sex Ross 308 broiler chicks at the age of 48 weeks breeding flock were obtained from a commercial firm. A total of 3360 chicks were divided into 2 groups (experimental and control) consisting of 3 replicates of 560 chicks with 12.6 birds $/ \mathrm{m}^{2}$ stocking density. During first 5 weeks, a sample of 112 (20\% of 530 chickens) randomly selected chicks from each group were weighed one by one, and later on at 6 weeks of age all were weighed in order to determine the mean weekly body weight of the groups. Feed consumption (pen basis) of chicks were measured weekly and the feed conversion ratio (FCR) was calculated by dividing feed consumption by body weight. Poultry house was heated with radiant heaters operating with LPG for the first 25 days. After the $25^{\text {th }}$ day, the heating requirement continued due to the winter season, and heating was ensured by attaching 4 thermostatic electric heaters to each batch and keeping the house temperature at $22-23^{\circ} \mathrm{C}$. As a litter, $5-6 \mathrm{~cm}$ highmaterial black pine shavings were used in both houses. The feeds used in the experiment were obtained from a commercial company. Table 1 below shows, provided feed types to the chicks and their nutritional profile according to the age.

Table 1. Types of feeds provided and nutritional profile of the chicks according to the age.

\begin{tabular}{lcccc}
\hline Nutrient Contents & Starter & Grower 1 & Grower 2 & Finisher \\
\hline Feed form & Granular & Granular & Pellets & Pellets \\
\hline Days & $0-10$ & $11-21$ & $22-35$ & $36-42$ \\
\hline Dry matter (\%) & 88 & 88 & 88 & 88 \\
Protein\% & 24 & 23 & 21 & 19 \\
Cellulose \% & 6.0 & 6.0 & 6.0 & 6.0 \\
Ash \% & 8.0 & 8.0 & 8.0 & 8.0 \\
Insoluble ash in HCl \% & 1.0 & 1.0 & 1.0 & 1.0 \\
Calcium\% & $1.0-1.5$ & $1.0-1.5$ & $0.9-1.5$ & $0.8-1.2$ \\
Phosphorus \% & 0.7 & 0.7 & 0.65 & 0.6 \\
Sodium \% & $0.15-0.30$ & $0.15-0.30$ & $0.15-0.30$ & $0.15-0.30$ \\
NaCl (Salt) \% & 0.35 & 0.35 & 0.35 & 0.35 \\
Lysine \% & 1.3 & 1.2 & 1.1 & 0.90 \\
Methionine \% & 0.6 & 0.5 & 0.5 & 0.35 \\
Cystine \% & 0.32 & 0.4 & 0.30 & 0.30 \\
Metabolic Energy (MJ/kg) & 13.39 & 13.39 & 13.39 & 13.39 \\
Metabolic Energy (Kcal/kg) & 3200 & 3200 & 3200 & 3200 \\
\hline
\end{tabular}

Lighting: In the control group, conventional lighting was applied and it is provided with 15 watt white light bulbs mounted $2 \mathrm{~m}$ above ground. Twelve (12) pieces of bulbs were placed in 2 lines at $3 \mathrm{~m}$ intervals. The intensity of the light at the level of nipples and drinkers in the control house was measured with the Lutron LX-101 model luxmeter and the light intensity was determined to be 18 lux. In the experimental house, nipple drinkers and feeders were illuminated by attaching white light point LEDs. In the experimental group, light intensity in the 
feeders was measured as 82 lux, 12 lux at the outer edge of the feeders, 1 lux at $15 \mathrm{~cm}$ distance from the feeders, 8 lux at the water dropper and zero in other areas (Figure
1). During the experiment, 23 hours of light 1 hour of darkness were applied to both control and experimental groups.

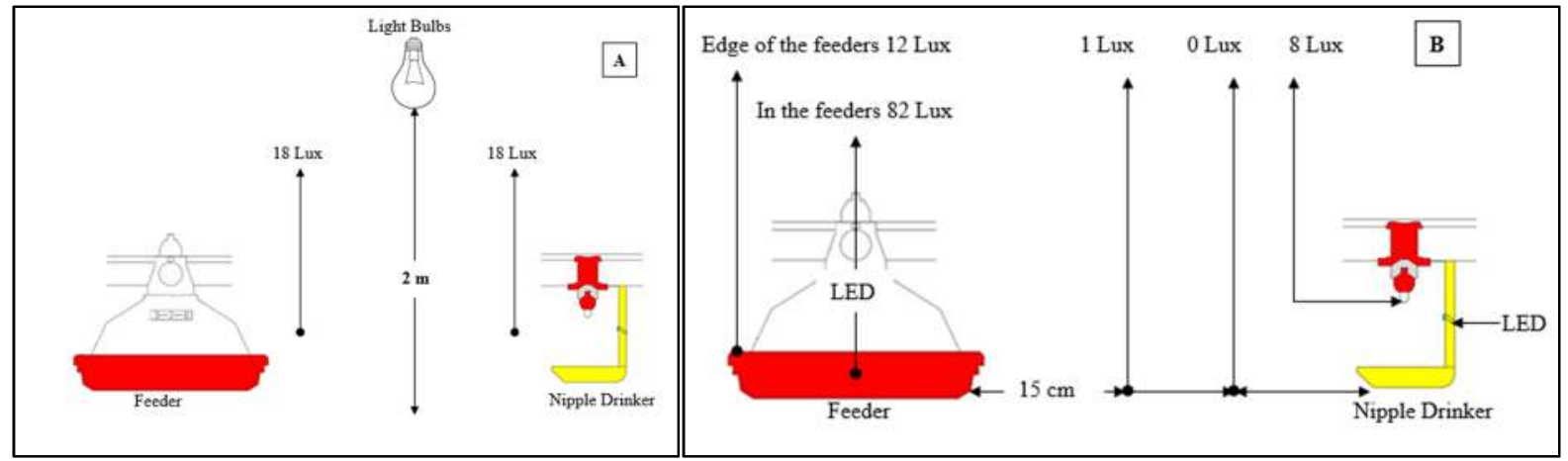

Figure 1. Lighting system and light intensity (A) Control (B) Experimental

Lighting of Feeders and Feeding: Six point LED lights were used for each feeder (Picture 2). Chicks started to be fed on the nylon (Picture 1) laid under spiral feeders, which also contains the feed inside. It is observed that the light reflecting from the point LEDs that are attached to the feeders, was sufficient for the chicks to be fed on the nylon over the ground.
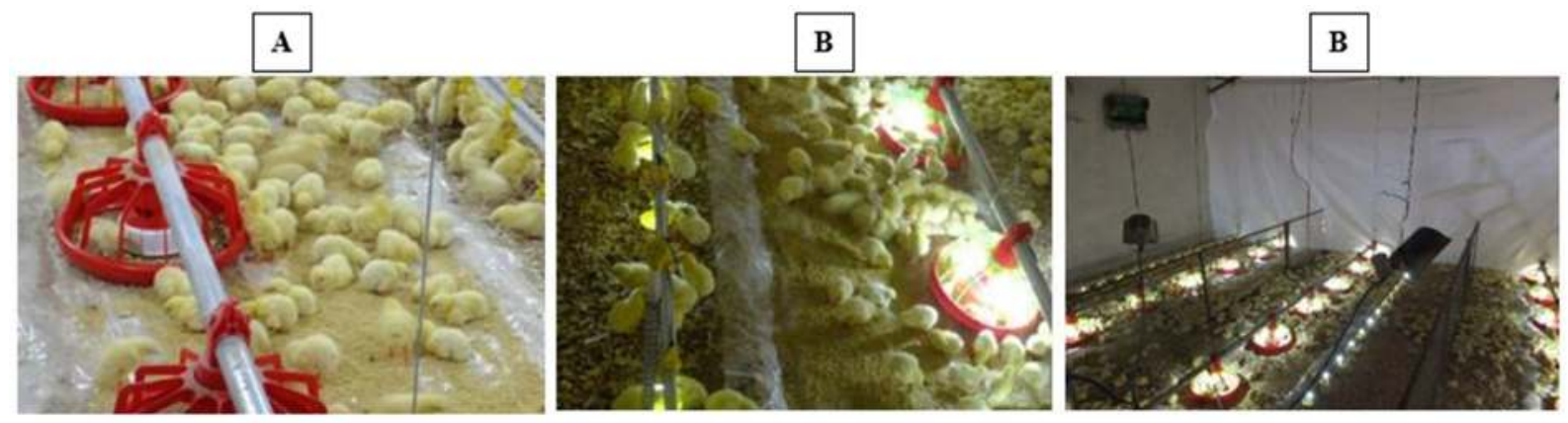

Picture 1. Feeding in the first days of control and experimental set (A) Control (B) Experimental

At the end of the first week, nylon tarpaulins were removed from the ground and only spiral feed plates remained as feeder. Throughout study, spiral feeders were automatically operated and ad-libitum feeding was

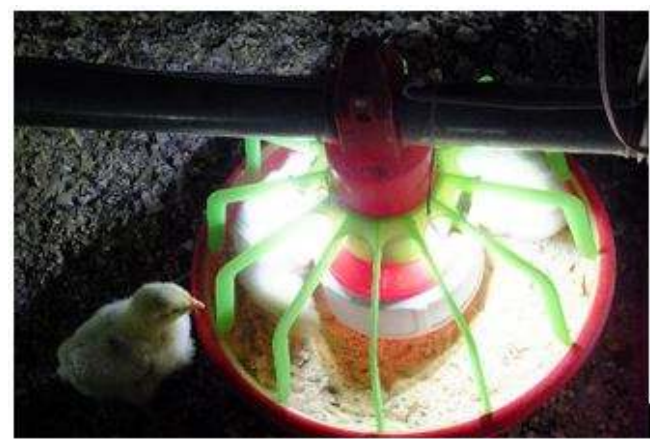

Picture 2. Lighting of experimental feeders

Lighting of nipple drinkers and watering: LED is attached to the dropper arm of all nipple drinkers and the applied. Each house contains three line of spiral feeding systems, one for each repeat. There were 21 feeders with $75 \mathrm{~cm}$ spacing on each line, and one $75 \mathrm{~kg}$ capacity feed silo for one line of spiral feeding system for each repeat.

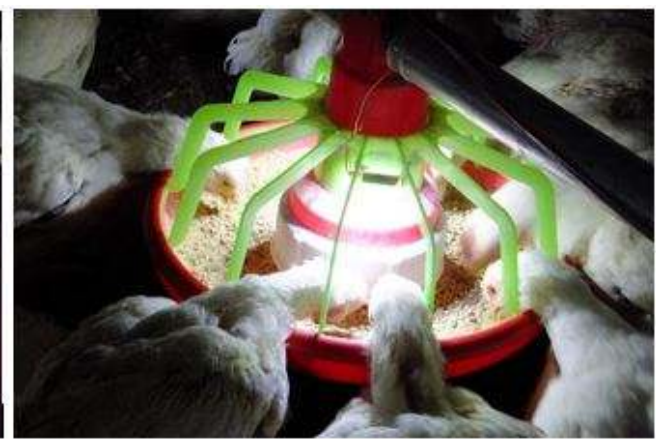

direction of light is adjusted according to the nipple (Picture 3). 


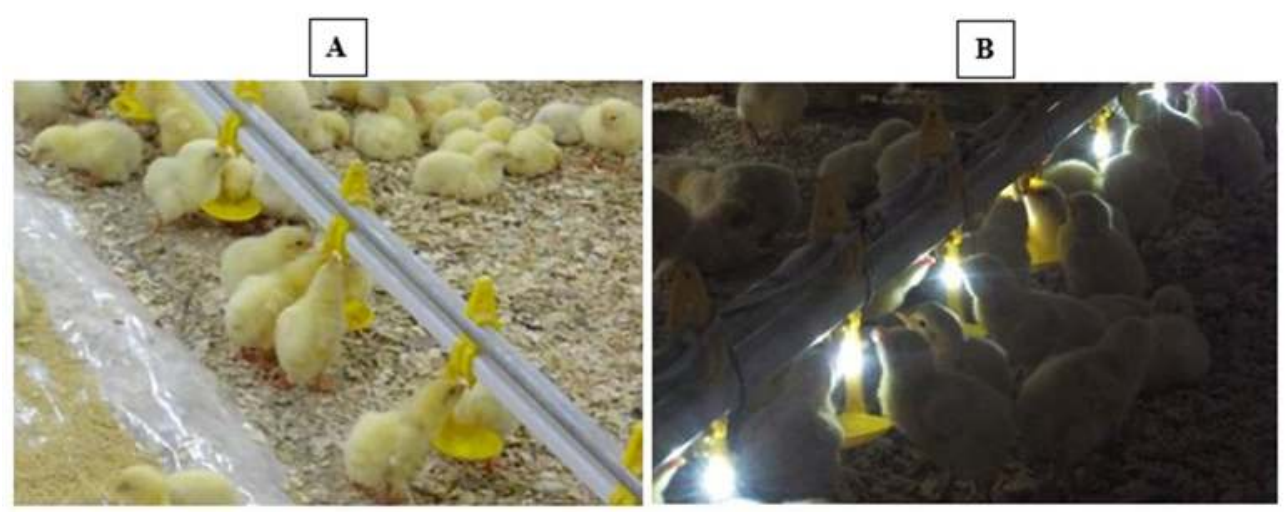

Picture 3. Nipple drinkers and lighting in control and experimental houses, (A) Control (B) Experimental

In each repeat one line of nipple drinker system was used and 67 nipple drinkers were placed at intervals of $20 \mathrm{~cm}$. Each group was provided one essential 500 liter-water tank and a 50 liter-water tank for vaccination. An overview of the control and experimental groups in the house is shown in Picture 4.
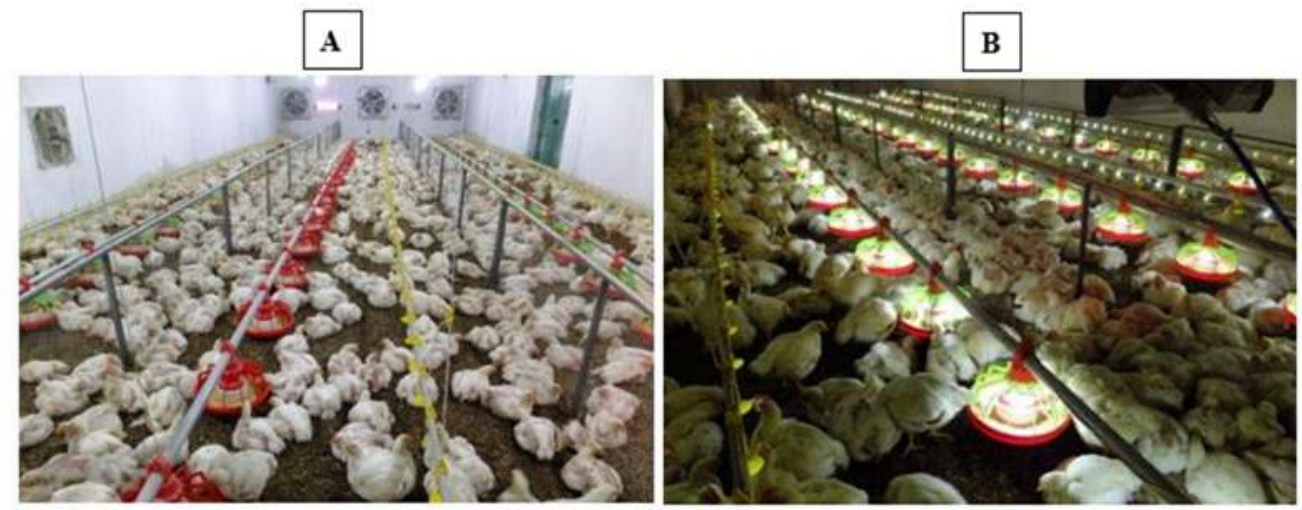

Picture 4. General image from control (a) and experimental (b) houses

Body weight, feed comsumption, FCR and mortality rates of the experimental group were measured and recorded for weeks, then compared with the control group, by using t-test SPSS V22.0 statistical package programme (SPSS, 2013).

\section{RESULTS AND DISCUSSION}

The effect of LED lighting system on the body weight of broiler: The effect of LED lighting system on the body weight and body weight gain of broiler is presented in Table 2. In terms of initial body weight there was no significant difference $(\mathrm{P}>0.05)$ between the experimental and control groups. Similarly, at the end of first week no change could be observed ( $\mathrm{P}>0.05)$ in the groups' body weight. However, as the weeks passed by, differences in the body weight between the two groups became more noticeable. At the end of the following weeks, there was an observable difference $(\mathrm{P} \leq 0.05, \mathrm{P} \leq 0.01)$ in the groups' body weight.
Recently some scientific studies, about lighting, on light color, lighting period, different light source and different lighting times in broilers etc. were carried out to explain the effects of light on broilers' body weights. In current researches; the effects of different light sources, the light intensities and the reduced illumination area on the performance measurings of broilers were examined. In this respect, all researches include mutual observations about the effects of light source, intensity and lighting programs. For instance, in a research conducted by Ilhan and Yetisir (2009), 20 and 5 lux light intensity were applied to broilers in 4 different lighting programs during three growing periods in order to analyse how the lighting affects broilers' body weight. And the results show that selected lighting programs and light intensity did not have a significant effect on the body weight of broilers at slaughtering age. The results obtained in this study are compatible with findings of Deep et al. (2010) who also reached to the conclusion that body weight and body weight gain were not affected by light intensity during all breeding periods. 
Table 2. The effect of LED lighting system on the weekly body weight gain and cumulative body weigth of broiler.

\begin{tabular}{lcccc}
\hline Age & \multicolumn{2}{c}{ Control } & \multicolumn{2}{c}{ Experimental } \\
\cline { 2 - 5 } & Weekly BW gain & Cumulative BW & Weekly BW gain & Cumulative BW \\
\hline Initial & - & $41.633 \pm 0.491$ & - & $41.700 \pm 0.351$ \\
1. week & $119.937 \pm 1.072$ & $161.654 \pm 0.861$ & $119.843 \pm 1.759$ & $161.491 \pm 0.994$ \\
2. week & $136.990 \pm 5.797$ & $299.286 \pm 2.984^{\mathrm{b}^{*}}$ & $148.133 \pm 2.883$ & $309.556 \pm 3.716^{\mathrm{a}^{*}}$ \\
3. week & $301.173 \pm 5.775$ & $598.906 \pm 6.441^{\mathrm{b}^{* *}}$ & $336.383 \pm 12.628$ & $646.582 \pm 6.778^{\mathrm{a}^{* *}}$ \\
4. week & $448.023 \pm 9.540$ & $1047.475 \pm 12.320^{\mathrm{b}^{* *}}$ & $473.273 \pm 15.140$ & $1119.623 \pm 11.762^{\mathrm{a}^{* *}}$ \\
5. week & $627.833 \pm 9.489$ & $1674.316 \pm 12.556^{\mathrm{b}^{* *}}$ & $656.363 \pm 4.944$ & $1776.099 \pm 14.922^{\mathrm{a}^{* *}}$ \\
6. week & $703.533 \pm 13.307$ & $2379.014 \pm 7.016^{\mathrm{b}^{* *}}$ & $670.917 \pm 11.240$ & $2446.639 \pm 7.114^{\mathrm{a}^{* *}}$ \\
\hline V.
\end{tabular}

Values are mentioned as Means $\pm \mathrm{SE}$, letter(s) in the same row with different superscripts are significantly different. ${ }^{*} \mathrm{P} \leq 0.05$, ${ }^{* *}$ $\mathrm{P} \leq 0.01$.

With their research, Deep et al. (2010) showed that light intensity, between 1 to 150 lux, had no significant effect on body weight, feed consumption and feed conversion ratio. Olanrewaju et al. (2016) carried out an experiment with 4 light sources and 2 levels (5 and 20 lux) of light intensities and unrevealed that the body weight, body weight gain and carcass weights of birds reared under cool poultry-specific filtered LED were different $(\mathrm{P} \leq 0.05)$ in comparison to birds reared under incandescent light source between the ages of 42 and 56 days. This difference was observed at the $3^{\text {rd }}, 4^{\text {th }}$ and 5 th weeks of this study. The results of this study also complies with findings of Nissa et al. (2018) who examined the effects of Natural (Control), Incandescent, $\mathrm{CFL}$, and LED light sources on broiler performance and drew a conclusion that there were no significant differences in the body weight and body weight gain of broiler, among the different experimental groups exposed to above mentioned light types respectively at the 42 days of age.

Today, a wide variety of lighting programs is used for broiler production (Baser and Yetisir, 2010). The light duration in a lighting program is one of the most significant components of the poultry applications (Aldridge, 2019) and can also have varying effects on performance, broiler activity, growth development and physiological functioning (Hogshead, 2015; Olanrewaju et al., 2015). Researches on different light duration mainly focus on two forms of lightning: continuous lighting and intermittent lighting (Zhao et al., 2019). Application of continuous lighting and intermittent lighting programs do not constitue any different results in terms of body weight (Altan et al., 1998; Bolukbasi and Yilmaz, 2003; Rahimi et al., 2005; Ilhan and Yetisir, 2009). It is reported that the intermittent lighting application $(2 \mathrm{~A} ; 2 \mathrm{~K})$ is superior to the application of continuous illumination (23A: 1K) (Classen et al., 1991; Classen et al., 2010) however when it comes to the need of darkness for animals, it was stated that the body weight was lowest in long-term (12A: 12K) application of darkness (Abbas et al., 2008). Reducing the duration of luminosity in the early period affects positively the foot development and decreases mortality rate however, it affects the chicks negatively in terms of the body weight gain (Sanotra et al., 2002). Mahmud et al. (2011) disclose that the groups exposed to daylight during the day and intermittent lighting at night, shows better results in terms of body weight when compared to the continuous light exposed group.

The lighting program is another factor that could affect animal welfare (Raccoursier Frost, 2016). According to the European Union ("EU") one continuous period of darkness for at least 4 hours is requested for animals'welfare. However, it is clarified that a period of darkness (less than 5 lux) of 8 hours is required for normal physiological activities (Bessei, 2006; Robins and Phillips, 2011). In this present study; beneficial aspects of both continuous and intermittent lighting program are presented as a combination. Although the experimental group was exposed to 23 hours of light and 1 hour of darkness, by using a lighting system which provides illumination for only feeders and drinkers, 0 lux illumination occurred in the rest of the house. In this system, broiler chickens can always satisfy their need for darkness without their performance and animal welfare being negatively affected. With this aspect, the lighting dimming envisaged for animal welfare is achieved. According to the research findings, how significant the absence of negativity in body weight and body weight gain is, has become clearer.

The effect of LED lighting system on feed intake of broiler: The effect of LED lighting system on feed intake of broiler is shown in Table 3. In terms of weekly and cumulative feed consumption, the difference between control and experimental groups was highly significant at the $3^{\text {rd }}$ and $4^{\text {th }}$ weeks $(P \leq 0.01)$, however at the end of the $5^{\text {th }}$ and $6^{\text {th }}$ weeks, nearly any difference could be observed between the control and experimental groups $(\mathrm{P}>0.05$, Table 3$)$. While the weekly feed consumption of the experimental group in the first four weeks was more than the consumption of the control group, the latter consumed more feed at the $5^{\text {th }}$ and $6^{\text {th }}$ weeks. Broilers in the experimental group were more interested in feeders during the first 4 weeks, but in the last two weeks they 
displayed a quieter behavior and spent more time in dark areas to rest;consequently feeders received less and less attention.

With regard to the feed intake different lighting studies showed distinctive results. In a study carried out in order to determine the effects of commonly used 20 and 5 lux light intensity in 4 different lighting programs on broiler performance (Ilhan and Yetisir, 2009), it was observed that cumulative feed consumption were not affected significantly by different lighting programs at slaughtering age except by one, and similarly the feed conversion ratio remained unaffected significantly during the growing period. In this study; although the results obtained at slaughtering age were similar in terms of cumulative feed consumption, statistical differences
$(\mathrm{P} \leq 0.01)$ were observed at the $3^{\text {rd }}$ and $4^{\text {th }}$ weeks. In other studies (Deep et al., 2010; Olanrewaju et al., 2016) conducted to determine the effects of light intensity $(1,5$, 10,20 and 40 lux) on broiler production, feed consumption and cumulative feed consumption remained unaffected by differentiating light intensity exposed for a period up to 35 days. Pan et al. (2019) affirm that in an unevenly distributed LED light environment, application of 30 lux or 60 lux of light intensity has no significant effect on feed intake of chicken broilers. The above mentioned researches lay out similar results with this present study, which was carried out with the application of different light intensities in the house $(0,1,12,82$ lux $)$ during a period up to 42 days.

Table 3. The weekly and cumulative feed (g) consumptions of experimental groups

\begin{tabular}{lcccc}
\hline \multirow{2}{*}{ Age } & \multicolumn{2}{c}{ Control } & \multicolumn{2}{c}{ Experimental } \\
\cline { 2 - 5 } & $\begin{array}{c}\text { Weekly Feed } \\
\text { Consumptions }\end{array}$ & $\begin{array}{c}\text { Cumulative Feed } \\
\text { Consumptions }\end{array}$ & $\begin{array}{c}\text { Weekly Feed } \\
\text { Consumptions }\end{array}$ & $\begin{array}{c}\text { Cumulative Feed } \\
\text { Consumptions }\end{array}$ \\
\hline 1. week & $136.17 \pm 1.184$ & $136.17 \pm 1.184$ & $140.43 \pm 1.725$ & $140.43 \pm 1.725$ \\
2. week & $208.30 \pm 0.252$ & $344.47 \pm 0.956$ & $211.50 \pm 1.250$ & $351.93 \pm 2.744$ \\
3. week & $413.77 \pm 1.697 \mathrm{~B}^{*}$ & $758.23 \pm 2.619 \mathrm{~b}^{* *}$ & $470.20 \pm 7.662 \mathrm{~A}^{*}$ & $822.13 \pm 6.028 \mathrm{a}^{* *}$ \\
4. week & $697.07 \pm 2.596$ & $1455.30 \pm 3.637 \mathrm{~b}^{* *}$ & $735.73 \pm 14.217$ & $1557.87 \pm 12.624 \mathrm{a}^{* *}$ \\
5. week & $1107.43 \pm 32.808$ & $2562.73 \pm 30.433$ & $1045.47 \pm 3.063$ & $2603.33 \pm 10.464$ \\
6. week & $1363.10 \pm 9.136$ & $3925.83 \pm 34.915$ & $1328.52 \pm 17.945$ & $3931.86 \pm 18.655$ \\
\hline
\end{tabular}

Values are mentioned as Means $\pm \mathrm{SE}$, letter(s) in the same row with different superscripts are significantly different. ${ }^{*}$ Significant at 0.05 probability level, ${ }^{* *}$ Significant at 0.01 probability level.

In the control group, the light intensity was 18 lux whereas in the experimental group, the light intensity was measured between 0 and 12 lux, below this value, in a large part of the house. Guo et al. (2018) express that broilers under low light intensity might have similar performances. The findings of the study are consistent with this view.

However, according to a study conducted by Nissa et al. (2018) to determine the effects of different light sources on the performance of broiler chicken, it is observed that the cumulative feed consumption differs significantly among different experimental groups, the lowest cumulative feed consumption is marked in groups which are exposed to LED $(3323.73 \pm 67.10 \mathrm{~g})$. Nonetheless, the opposite result was obtained in this present study, in other words cumulative feed consumption was determined higher at the $3^{\text {rd }}$ and $4^{\text {th }}$ weeks in the group exposed to LED light source, compared to the control group.

Abbas et al. (2008) claim that the lowest feed intake is marked in $12 \mathrm{~A}-12 \mathrm{~K}$ treatment. Some researchers who applied short-term darkness reported that they could not observe any difference between groups in terms of feed consumption. (Altan et al., 1998; Bolukbasi and Yilmaz, 2003; Rahimi et al., 2005; Mahmud et al., 2011). According to Zhao et al. (2019), the intermittent lighting has a significant effect on daily average feed intake of broiler chickens compared with constant lighting. Zhao et.al.suggest that the intermittent lighting might be beneficial to broiler chickens from 1 to 21 days of age. Although 23 hours of light and 1 hour darkness were applied in this study, 0 lux lighting was observed in the areas other than feeders and drinkers. In the applied lighting system, the broilers were exposed to continuous lighting during feed intake and drinking activities and intermittent lighting the rest of the time. Higher feed intake was observed at the $3^{\text {rd }}$ and $4^{\text {th }}$ weeks of age in the experimental group compared to control group and the results of this study indicates no negative effects of continuous and intermittent lighting systems used conjointly.

The effect of LED lighting system on the feed conversion ratios (FCR): In terms of feed conversion statistically significant differences were observed between the two groups at the end of the $1^{\text {st }}$ week $(\mathrm{P} \leq 0.05), 5^{\text {th }}$ week $(\mathrm{P} \leq 0.01)$. Cumulative feed conversion ratio at 6 weeks of age was determined as 1.651 and 1.607 in the control and experimental groups, respectively $(\mathrm{P}>0.05)$. In the last two weeks, although the lack of physical activity in the experimental group caused a decrease in feed consumption and body weight gain, 
this situation had positive impacts on the feed conversion ratio (Table 4).

No statistically significant difference was determined in the studies conducted to explain the effects of light intensity (Newberry et al., 1988; Prayitno et al., 1997; Ilhan and Yetisir, 2009; Deep et al., 2010; Olanrewaju et al., 2011), lighting period (Altan et al., 1998; Bolukbasi and Yilmaz, 2003; Aksit et al., 2017) on the feed conversion ratio. However, the effect of photoperiod on the feed conversion ratio were perceived as significant in the recent studies (Rahimi et al. 2005; Abbas et al., 2008; Classen et al., 1991; Classen et al., 2010; Mahmud et al., 2011).
Ahmad et al. (2011) and Olanrewaju et al. (2014 b) claim that low lighting environment optimizes feed conversion. In this study, the values obtained from the $5^{\text {th }}$ week are consistent with this view. On the other hand, feed conversion results of the first week were high in the experimental group. The essential reason of this difference, is the fact that the experimental group displayed more physical activity around the feeder and drinker during the $1^{\text {st }}$ week than the following weeks. In another study researching the effect of different light source on broiler production (Nissa et al., 2018), the results of feed conversion on the $42^{\text {nd }}$ day were better in the LED lighting exposed-group. A similar result was also obtained at $5^{\text {th }}$ week in this study.

Table 4. Weekly and cumulative feed conversion ratio values in experimental groups.

\begin{tabular}{lcccc}
\hline \multirow{2}{*}{ Age } & \multicolumn{2}{c}{ Control } & \multicolumn{2}{c}{ Experimental } \\
\cline { 2 - 5 } & Weekly & Cumulative & Weekly & Cumulative \\
\hline 1. week & $1.135 \pm 0.005^{\mathrm{A}^{*}}$ & $0.843 \pm 0.010^{\mathrm{b}^{*}}$ & $1.172 \pm 0.009^{\mathrm{B}^{*}}$ & $0.869 \pm 0.012^{\mathrm{a}^{*}}$ \\
2. week & $1.526 \pm 0.064$ & $1.154 \pm 0.034$ & $1.429 \pm 0.020$ & $1.137 \pm 0.015$ \\
3. week & $1.375 \pm 0.026$ & $1.264 \pm 0.009$ & $1.400 \pm 0.039$ & $1.273 \pm 0.028$ \\
4. week & $1.557 \pm 0.038$ & $1.389 \pm 0.025$ & $1.556 \pm 0.029$ & $1.391 \pm 0.012$ \\
5. week & $1.763 \pm 0.038^{\mathrm{A}^{*}}$ & $1.530 \pm 0.016^{\mathrm{a}^{* *}}$ & $1.593 \pm 0.010^{\mathrm{B}^{*}}$ & $1.466 \pm 0.013^{\mathrm{b}^{* *}}$ \\
6. week & $1.938 \pm 0.050$ & $1.651 \pm 0.023$ & $1.980 \pm 0.019$ & $1.607 \pm 0.012$ \\
\hline
\end{tabular}

Values are mentioned as Means \pm SE, letter(s) in the same row with different superscripts are significantly different. ${ }^{*}$ Significant at 0.05 probability level, ${ }^{* *}$ Significant at 0.01 probability level.

Zhao et al. (2019), state that photoperiods and light intensities have no effect on average feed conversion ratio of the broiler chickens from 1 to 21 days of age. A similar result was obtained in the $3^{\text {rd }}$ week cumulative feed values in this study. In this study, although continuous lighting program $(23 \mathrm{~L}, 1 \mathrm{D})$ has been applied, continuous dark areas were also kept reserved within the house. This aspect has similarities with intermittent lighting programs. In a research conducted by Yang et al. (2015) analysing the effects of intermittent lighting on broiler growth performance, it has been shown that the feed conversion of broilers raised in the 4L:4D intermittent lighting programs are significantly more efficient than broilers in continuous lighting program.

The effect of LED lighting system on the Mortality: The mean weekly mortality rate in the first week was $1.37 \%$ in the control group, while the average of the experimental group was $0.71 \%(\mathrm{P} \leq 0.05)$. The mortality rates for the $6^{\text {th }}$ week(at the end of experiment) were $0.87 \%$ in the control group and $0.43 \%$ in the experimental group $(\mathrm{P} \leq 0.01)$. At the end of the 42-day experiment, the total mortality rate were $5.24 \%$ in the control group and $3.51 \%$ in the experimental group and this statistics reveals a significant difference $(\mathrm{P} \leq 0.05$, Table 5).
Although lighting program has been proven to have a significant effect on the mortality according to some studies (Classen et al., 2010; Brown, 2010; Ahmad et al., 2011; Maria et al. 2011; Schwean-Lardner et al., 2013; Skrbic et al., 2015), it has not been examined in many studies in other respects. (Rahimi et al., 2005; Deep et al., 2010, Olanrewaju et al., 2014 a, b; 2016; Evrim et al., 2017; Nissa et al., 2018; Zhao et al., 2019; Pan et al., 2019).

In conclusion, it was clearly seen that the results of this study differed from each other depending on the application of different lighting experiments. In this study, unlike any other scientific researches so far conducted. LED light sources were used. The LED light source was used solely in the lighting of feeders and drinkers in the continuous lighting program (23L, 1D) so that different light intensities $(0,1,12,82$ lux $)$ could be created at different spots in the house. Concerning cumulative mortality, the data obtained from the experimental group was statistically different from the control group along the experiment and the experimental group's longevity was determined higher. In this research, no negative effect of the LED light source use on the longevity of broiler chickens is observed.

The areas of darkness will be more advantageous since there are wider distances between feeders and drinkers in commercial houses, chickens are expected to benefit more from darkness and by doing so they can also 
save more energy. In this aspect, point LED Lights system can be used as lighting system in broiler production being cost effective without compromising the productive performance. This study is recommended to be re-conducted in commercial large houses.

Table 5. Weekly and cumulative mortality rates in experimental groups (\%).

\begin{tabular}{ccccc}
\hline \multirow{2}{*}{ Age } & \multicolumn{2}{c}{ Control } & \multicolumn{2}{c}{ Experimental } \\
\cline { 2 - 5 } & Weekly & Cumulative & Weekly & Cumulative \\
\hline 1. week & $1.370 \pm 0.159^{\mathrm{A}^{*}}$ & $1.370 \pm 0.159^{\mathrm{a}^{*}}$ & $0.713 \pm 0.101^{\mathrm{B}^{*}}$ & $0.713 \pm 0.101^{\mathrm{b}^{*}}$ \\
2. week & $0.600 \pm 0.060$ & $1.963 \pm 0.101^{\mathrm{a}^{* *}}$ & $0.360 \pm 0.104$ & $1.070 \pm 0.104^{\mathrm{b}^{* *}}$ \\
3. week & $0.910 \pm 0.180$ & $2.860 \pm 0.104^{\mathrm{a}^{* *}}$ & $0.960 \pm 0.216$ & $2.023 \pm 0.117^{\mathrm{b}^{* *}}$ \\
4. week & $0.797 \pm 0.161$ & $3.630 \pm 0.216^{\mathrm{a}^{*}}$ & $0.610 \pm 0.060$ & $2.620 \pm 0.159^{\mathrm{b}^{*}}$ \\
5. week & $0.800 \pm 0.060$ & $4.403 \pm 0.156^{\mathrm{a}^{*}}$ & $0.487 \pm 0.162$ & $3.093 \pm 0.297^{\mathrm{b}^{*}}$ \\
6. week & $0.870 \pm 0.065^{\mathrm{a}^{* *}}$ & $5.240 \pm 0.216^{\mathrm{a}^{*}}$ & $0.430 \pm 0.060^{\mathrm{B}^{* *}}$ & $3.513 \pm 0.331^{\mathrm{b}^{*}}$ \\
\hline
\end{tabular}

Values are mentioned as Means $\pm \mathrm{SE}$, letter(s) in the same row with different superscripts are significantly different. ${ }^{*}$ Significant at 0.05 probability level, ${ }^{* *}$ Significant at 0.01 probability level.

Acknowledgements: This study was supported by the Scientific Research Projects Coordination Unit (BAP) of Kahramanmaraş Sütçü Imam University with 2013/6-31 project number.

\section{REFERENCES}

Abbas, A.O., A.K. Alm El-Dein, A.A. Desoky and M.A.A. Galal (2008). The effects of photoperiod programs on broiler chicken performance and immune response. Int. J. of Poult. Sci., 7(7): 665-671. doi:10.3923/ijps.2008.665.671.

Ahmad, F., A. U. Haq, M. Ashraf, G. Abbas and M. Z. Siddiqui (2011). Effect of different light intensities on the production performance of broiler chickens. Pakistan Vet. J. 31(3): 203-206.

Aksit, M., I.B. Helva and Z. Kacamakli Yardim (2017). The effect of different stocking density and intermittent lighting on performance and tibial bone characteristics in broilers. Hayvansal Üretim 58(2): 45-51.

Aldridge, D. J. (2019). Optimization of the light environment for broiler chickens. Theses and Dissertations. 3285 . https://scholarworks.uark.edu/etd/3285

Altan, O., A. Altan and S. Ozkan (1998). Effects of different lighting treatment on broiler performance. Tr. J. of Vet. and Anim. Sci., 22(14): 97-102.

Archer, G.S. (2015). Comparison of incandescent, CFL, LED and bird level LED lighting: growth, fear and stress. Int. J. Poult. Sci., 14: 449-455.

Baser, E. and R. Yetisir (2010). Effects of different lighting schedules on broiler performance and welfare. Hayvansal Üretim 51(2): 68-76.

Bessei, W. (2006). Welfare of broilers: A review. World`s Poult. Sci., J. 62:455-466.

Blair, R., R.C. Newberry and E.E. Gardiner (1993). Effects of lighting pattern and dietary tryptophan supplementation on growth and mortality in broilers. Poult. Sci., 72(3): 495-502. doi:10.3382/ps.0720495.

Blatchford R. A., G. S. Archer and J. A. Mench (2012). Contrast in light intensity, rather than day length, influences the behavior and health of broiler chickens. Poult. Sci., 91: 17681774. doi:10.3382/ps.2011-02051

Bolukbasi, S. and C. M. Yilmaz (2003). The effect of intermittent lighting schedule on growth performance of broilers. Atatürk University, Ziraat Fak. Dergisi. 34(3): 245-248. http://dergipark.gov.tr/download/articlefile/34300.

Brown, A. J. (2010). Photoperiod effects on broiler performance and behaviour. B.S. Virginia Polytechnic Institute and State University, Master Thesis, https://getd.libs.uga.edu/pdfs/brown_anthony_j_ 201005_ms.pdf

Classen, H.L. and C. Riddell (1989). Photoperiodic effects on performance and leg abnormalities in broiler chickens. Poult. Sci. 68(7): 873-879. doi: $10.3382 / \mathrm{ps} .0680873$.

Classen, H.L., C. Riddell and F.E. Robinson (1991). Effects of increasing photoperiod length on performance and health of broiler chickens. Bri. Poult. Sci., 32(1): 21-29. doi:10.1080/00071669108417324.

Classen, H.L., C.B. Annett, K.V. Schwean-Lardner, R. Gonda and D. Derow (2010). The effects of lighting programmes with twelve hours of darkness per day provided in one, six or twelve hour intervals on the productivity and health of broiler chickens. Bri. Poult. Sci., 45(1): 31-32. doi:10.1080/00071660410001698137.

Deep, A., K. Schwean-Lardner, T.G. Crowe , B.I. Fancher and H.L. Classen (2010). Effect of light intensity on broiler production, processing 
characteristics, and welfare. Poult. Sci., 89: 2326-2333.

Evrim D.F., A. Nazligul, M. K. Turkyilmaz, S. Karaarslan and M. Kaya (2017). Effects of photoperiod length and light intensity on performance, carcass characteristics and heterophil to lymphocyte ratio in broilers. Kafkas Univ. Vet. Fak. Dergisi, 23:39-45.

Guo Y.L., S.M. Ma, J.J. Du and J.L. Chen. (2018). Effects of light intensity on growth, anti-stress ability and immune function in yellow feathered broilers. Brazilian J. of Poult. Sci., v.20/n.1/079084.

Hogshead, B. (2015) The Effects of light color on the performance and immune response of broiler chickens. The Ohio State Univ. Depart. of Anim. Sci. Undergraduate Research Theses

Huth, J.C. and G.S. Archer (2015). Comparison of two LED light bulbs to a dimmable CFL and their effects on broiler chicken growth, stress and fear. Poult. Sci., 94: 2027-2036

Ilhan, U. and R. Yetisir (2009). Comparison of lighting programs widely used in broiler production with respect to performance and some carcass properties. Selcuk Uni., Selcuk Tarim ve Gida Bilimleri Dergisi. 23(47): 63-72.

Mahmood S., F. Ahmad, A. Haq, G. Abbas, R. A. Qureshi, M. Fiaz, T. Ahmad, M. Saleem and M. K. Shahzad. (2014). Comparative effect of light intensity on behavior and blood profile in broilers. Scholar's Advances in Animal and Vet. Research, 1(1): 25-29.

Mahmud, A., Saima, Rafiullah and I. Ali (2011). Effect of different light regimens on performance of broilers. J. Anim. Plant Sci. 21(1):104-106.

Maria, V., N. Abreu, P. G. de Abreu, A. Coldebella, F. Regina F. Jaenisch, J. I. S. Filho and D. P. Paiva (2011). Curtain color and lighting program in broiler production: I-general performance. Accessed on $\mathrm{H}: \mathrm{lLight}$ Color $\backslash \mathrm{Wb}$ page $\backslash$ scielo.php.htm

Newberry, R.C., J.R. Hunt and E.E. Gardiner (1988). Influence of light intensity on behavior and performance of broiler chickens. Poult. Sci. 67(7): 1020-1025. doi:10.3382/ps.0671020.

Nissa, S.S., I.U. Sheikh, M.T. Banday, A.A Khan, B. Zaffer and S. Shafiq (2018). Effect of different light sources on the performance of broiler chicken reared under deep litter system of management. J. of Entomology and Zoology Studies, 6(4): 398-400

Olanrewaju, H.A., J.P. Thaxton, W.A. Dozier III, J. Purswell, W.B. Roush and S.L. Branton (2006). A Review of lighting programs for broiler production. Int. J. of Poult. Sci. 5(4): 301-308
Olanrewaju, H.A., J.L. Purswell, S.D. Collier and S.L. Branton. (2011). Effect of varying light intensity on growth performance and carcass characteristics of broiler chickens grown to heavy weights. Int. J. Poult. Sci. 10(12): 921 926.

Olanrewaju H.A., W.W. Miller, W.R. Maslin, S.D. Collier, J.L. Purswell and S.L. Branton. (2014a). Effects of strain and light intensity on growth performance and carcass characteristics of broilers grown to heavy weights. Poult. Sci. 93(8):1890-1899. doi.org/10.3382/ps.201303806

Olanrewaju H.A., J.L. Purswell, S.D. Coller and S.L. Ranton (2014b). Effects of genetic strain and light intensity on blood physiological variables of broilers grown to heavy weights. Poult. Sci., 93(4): 970-978. doi.org/10.3382/ps.2013-03613

Olanrewaju H.A., W.W. Miller, W.R. Maslin, S.D. Collier, J.L. Purswell and S.L. Branton, (2015). Influence of photoperiod, light intensity and their interaction on health indices of modern broilers grown to heavy weights. Int. J. of Poult. Sci., 14: 183-190.

Olanrewaju, H.A., W.W. Miller, W.R. Maslin, S.D. Collier, J.L. Purswell and S.L. Branton (2016). Effects of light sources and intensity on broilers grown to heavy weights. Part 1: growth performance, carcass characteristics, and welfare indices. Poult. Sci. 95(4): 727-735 doi:org/10.3382/ps/pev360.

Pan, C., M. Lu, Y. Zhang, Y. Yu, Q. Liu, Y.Y. Yang and J. Pan (2019). Unevenly distributed LED light produces distinct behavioral preferences and production performance of broilers. Int J. Agric \& Biol Eng. 12(2): 49-53.

Pandey U. (2019) Effect of lighting in broiler production. Acta Scientific Agri. 3(6) 114-116. doi: 10.31080/ASAG.2019.03.0485

Prayitno, D.S., C.J. Phillips and D.K. Stokes (1997). The effects of color and intensity of light on behavior and leg disorders in broiler chickens. Poult. Sci. 76(12): 1674-1681. doi:10.1093/ps/76.12.1674.

Raccoursier Frost, M. (2016). Effect of light intensity on production parameters and feeding behavior of broilers. Theses and Dissertations, 1854. http://scholarworks.uark.edu/etd/1854

Rahimi, G., M. Rezaei, H. Hafezian and H. Saiyahzadeh (2005). The effect of intermittent lighting schedule on broiler performance. Int. J. of Poult. Sci. 4(6): 396-398. doi:10.3923/ ijps. 2005.396.398.

Renden, J.A., S.F. Bilgili, R.J. Lien and S.A. Kincaid (1991). Live performance and yields of broilers provided various schedules. Poult. Sci. 70(10): 2055-2062. doi:10.3382/ps.0702055. 
Robins A. and C.J.C. Phillips (2011). International approaches to the welfare of meat chickens. World's Poult. Sci. J. 67(2): 351-369. doi.org/10.1017/S0043933911000341

Rozenboim, I., B. Robinzon and A. Rosenstrauch (2010). Effect of light source and regimen on growing broilers. Bri. Poult. Sci. 40(4): 452-457. doi:10.1080/00071669987197.

Sanotra, G.S., J. Damkjer Lund and K.S. Vestergaard (2002). Influence of light-dark schedules and stocking density on behavior, risk of leg problems and occurrence of chronic fear in broilers. Bri. Poult. Sci. 43(3): 344-354. doi: 10.1080/ 000716601201036023611.

Schwean-Lardner, K., B.I. Fancher, S. Gomis, A. Van Kessel, S. Dalal and H.L. Classen (2013). Effect of day length on cause of mortality, leg health, and ocular health in broilers. Poult. Sci. 92(1): 111. doi.org/10.3382/ps.2011-01967

Skrbic, Z., Z. Pavlovski, M. Lukic and V. Petricevic (2015). Incidence of footpad dermatitis and hock burns in broilers as affected by genotype, lighting program and litter type. Ann. Anim. Sci.15(2): 433-445. doi: 10.1515/aoas-20150005

SPSS. (2013). IBM United States Software Announcement 213-309, dated August 13, 2013

Yang H., H. Xing, Z. Wang, J. Xia, Y. Wan, B. Hou and J. Zhang (2015). Effects of intermittent lighting on broiler growth performance, slaughter performance, serum biochemical parameters and tibia parameters. Ital. J. Anim. Sci., 14(4): Artic. 4143. https://doi.org/10.4081/ijas.2015.4143

Zhao R.X., C.H. Cai, P. Wang, L. Zheng, J.S. Wang, K.X. Li, W. Liu, X.Y. Guo, X. A. Zhan and K.Y. Wang (2019). Effect of night light regimen on growth performance, antioxidant status and health of broiler chickens from 1 to 21 days of age. Asian-Australasian J. of Anim. Sci. 32(6): 904-911. doi: 10.5713/ajas.18.0525. 